\title{
Status of insecticide resistance in high-risk malaria provinces in Afghanistan
}

\author{
Mushtaq Ahmad', Cyril Buhler², Patricia Pignatelli ${ }^{3}$, Hilary Ranson³ , Sami Mohammad Nahzat ${ }^{4}$, \\ Mohammad Naseem ${ }^{1}$, Muhammad Farooq Sabawoon ${ }^{1}$, Abdul Majeed Siddiqi ${ }^{1}$ and Martijn Vink ${ }^{5^{*}}$ (i)
}

\begin{abstract}
Background: Insecticide resistance seriously threatens the efficacy of vector control interventions in malaria endemic countries. In Afghanistan, the status of insecticide resistance is largely unknown while distribution of longlasting insecticidal nets has intensified in recent years. The main objective of this study was thus to measure the level of resistance to four classes of insecticides in provinces with medium to high risk of malaria transmission.

Methods: Adult female mosquitoes were reared from larvae successively collected in the provinces of Nangarhar, Kunar, Badakhshan, Ghazni and Laghman from August to October 2014. WHO insecticide susceptibility tests were performed with DDT (4\%), malathion (5\%), bendiocarb (0.1\%), permethrin (0.75\%) and deltamethrin (0.05\%). In addition, the presence of $k d r$ mutations was investigated in deltamethrin resistant and susceptible Anopheles stephensi mosquitoes collected in the eastern provinces of Nangarhar and Kunar.
\end{abstract}

Results: Analyses of mortality rates revealed emerging resistance against all four classes of insecticides in the provinces located east and south of the Hindu Kush mountain range. Resistance is observed in both An. stephensi and Anopheles culicifacies, the two dominant malaria vectors in these provinces. Anopheles superpictus in the northern province of Badakhshan shows a different pattern of susceptibility with suspected resistance observed only for deltamethrin and bendiocarb. Genotype analysis of knock down resistance ( $k d r)$ mutations at the voltage-gated channel gene from An. stephensi mosquitoes shows the presence of the known resistant alleles L1014S and L1014F. However, a significant fraction of deltamethrin-resistant mosquitoes were homozygous for the $1014 \mathrm{~L}$ wild type allele indicating that other mechanisms must be considered to account for the observed pyrethroid resistance.

Conclusions: This study confirms the importance of monitoring insecticide resistance for the development of an integrated vector management in Afghanistan. The validation of the kdr genotyping PCR assay applied to An. stephensi collected in Afghanistan paves the way for further studies into the mechanisms of insecticide resistance of malaria vectors in this region.

Keywords: Insecticide resistance, Afghanistan, Anopheles stephensi, Knock down resistance (kdr) mutation, Organochlorides, Pyrethroids, Carbamates, Organophosphates

\section{Background}

Malaria is a significant health problem in Afghanistan with more than eight million people still living in high transmission areas [1]. Malaria transmission is seasonal with the vast majority of cases recorded from June to

\footnotetext{
*Correspondence: martijn.vink@hntpo.org

${ }^{5}$ HealthNet TPO, Lizzy Ansinghstraat 163, 1072 RG Amsterdam,

The Netherlands

Full list of author information is available at the end of the article
}

November [2]. The Hindu Kush mountain range and the arid climate in the south result in transmission areas restricted to snow-fed river valleys and irrigated zones below $2000 \mathrm{~m}$ above sea level [3]. Plasmodium vivax accounts for $95 \%$ and Plasmodium falciparum for $5 \%$ of the malaria cases. In 2013, 39,263 confirmed malaria cases were recorded [1] and, in endemic areas, the prevalence of $P$. vivax is above $5 \%$ [3].

Amongst the numerous Anopheles species present in the country, the principal malaria vectors are Anopheles 
superpictus, Anopheles culicifacies, Anopheles hyrcanus, Anopheles pulcherrimus and Anopheles stephensi [4]. The extensive DDT-based spraying programmes conducted from 1950 s to early 1970 s resulted in a near eradication of An. superpictus, the main malaria vector in the country. Unfortunately, An. stephensi and to a lesser extent An. culicifacies had become resistant to DDT in the south and eastern provinces bordering Pakistan and have replaced the An. superpictus populations in these regions $[2,4]$. The development of new cultivated areas in the North also led to the selection or re-emergence of the outdoor resting An. pulcherrimus and An. hyrcanus populations which represent now the two main malaria vectors observed in the rice fields of Kunduz province [3, $5]$ and in the wider region including the southern part of Tajikistan [6]. Due to its ability to survive at relatively high altitude, An. superpictus seems to be now mostly restricted to freshwater breeding sites in valleys of the Hindu Kush mountain range [7].

Vector control interventions are cost effective and essential measures to control malaria $[8,9]$. The lack of an effective malaria vaccine and the presence or emergence of resistance to existing anti-malarial drugs further increases reliance on indoor residual spraying (IRS) and distribution of long-lasting insecticidal nets (LLINs) to control malaria vectors. Between 1949 and 1973 IRS campaigns have been conducted across the country, first with DDT and then (when this pesticide lost is effectiveness) with malathion. In the years thereafter, small-scale spraying campaigns were conducted with insecticides supplied by the USSR, Iraq and the UK, but after the Soviet invasion in 1979 IRS campaigns in the country stopped altogether [4]. Since 2001 IRS has been implemented occasionally but only on a local scale to control malaria epidemics. In the beginning of the 1990s insecticide-treated nets (ITNs) were introduced in Afghan refugee camps in Pakistan and from 1992 in Afghanistan itself. The ITNs were treated-and later retreated-with deltamethrin, permethrin or alpha-cypermethrin. From 2007, ITNs were replaced by LLINs and a universal free coverage of LLINs was implemented through house-tohouse distribution campaigns. Between 2007 and 2015, more than nine million deltamethrin-treated LLINs were distributed to households in the main malaria-endemic provinces across the country as defined by a risk stratification map developed by the WHO and the Ministry of Public Health (MoPH) [10]. Further LLINs distribution is still ongoing in the country and is coordinated by a Vector Borne Disease Task Force at the Ministry of Public Health.

Only four classes of insecticides are currently approved for IRS: organochlorides, organophosphates, carbamates and pyrethroids [11]. The situation with LLINs is even more problematic as pyrethroids are the only insecticide class approved for safety reasons and efficacy [12]. The repeated use of the same insecticides combined with agriculture pesticide usage has maintained a selection pressure amongst mosquito populations leading inevitably to the development of insecticide resistance in many African malaria endemic countries [13]. Resistance to several insecticides have also been reported in the Middle East region including DDT resistance in Iran [14] and pyrethroid resistance in An. stephensi in Dubai [15], although such monitoring is less developed than in the sub-Saharan or East African region (see the current status of insecticide resistance worldwide on the IR mapper interactive tool [16]). Data on insecticide susceptibility in Afghanistan is still very limited and further complicated by the number of endemic Anopheles species present in the country. The latest and only data available so far come from a susceptibility study conducted by the National Malaria and Leishmaniasis Control Programme (NMLCP) of the MoPH in 2010 that showed a reduction in susceptibility to pyrethroids, carbamates and organochlorines especially in the eastern province of Nangarhar [10]. Accurate measures of insecticide resistance in Afghanistan are thus essential to aid the Vector Borne Disease Task Force with an evidence base to evaluate current vector management interventions, raise awareness in case of increased resistance to specific insecticides and adapt local strategies based on mosquito population dynamics.

With the growing threat and challenges posed by insecticide resistance in malaria endemic countries, the WHO and Roll Back Malaria have developed the global plan for insecticide resistance management (GPIRM) [13]. Thus, in agreement with the recommendations of the GPIRM, a study was developed to survey the level of resistance in a selection of Afghan provinces. A recent malaria risk stratification at the district level was used to select districts in five high risk malaria provinces for this study: the eastern provinces of Laghman, Nangarhar and Kunar known for the highest rate of $P$. falciparum malaria transmission, the southern province of Ghazni and the northern province of Badakhshan (Fig. 1). As recommended by the WHO, a separate study was implemented to gather information on the underlying mechanisms of resistance. This study focused on target site resistance by assessing the presence of knock down resistance $(k d r)$ mutations in the voltage-gated channel gene using an allele specific PCR approach previously developed for An. stephensi in India [17].

\section{Methods}

\section{Study sites}

Larvae collections were conducted successively in the eastern provinces of Nangarhar, Kunar and Laghman, the 


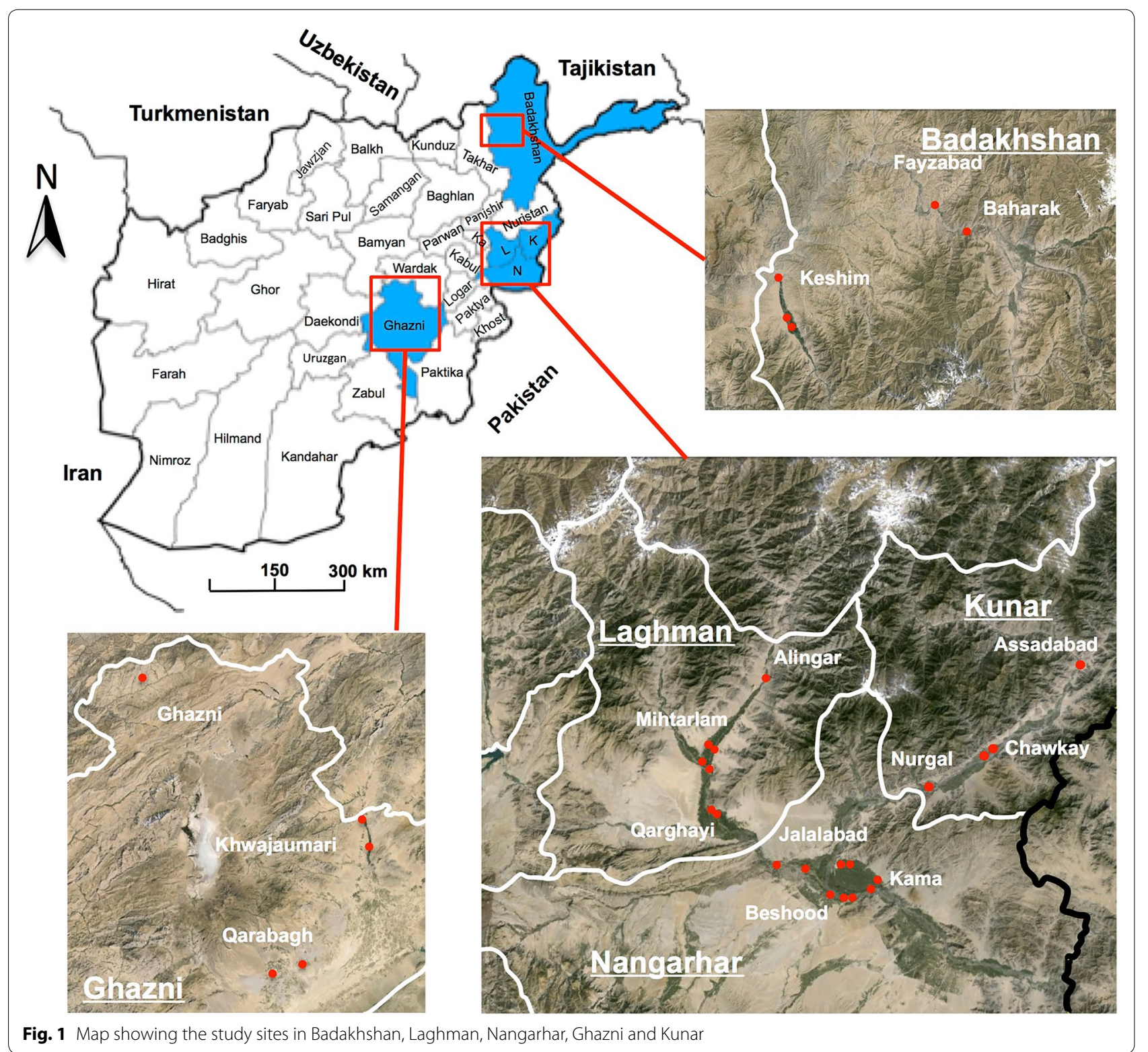

northern province of Badakhshan and the southern province of Ghazni from August to October 2014. In order to obtain a good representation of insecticide susceptibility at the provincial level at least three districts described as medium to high-risk malaria transmission by the NMLCP were selected within each province [10]. Locations of the study sites are indicated in Fig. 1 and ecological characteristics of each collection site are provided in Table 1.

\section{Larval collection and mosquito rearing}

In each province, immature stage mosquitoes (larvae or pupae) were collected from breeding sites located within a 2 to $3-\mathrm{km}$ radius in ecological habitats where the probability to find larvae was high (river stream, rice fields, water puddles or other standing water areas). Sites with the highest densities were used for sampling to obtain enough test subjects for the susceptibility assays.

Larvae samples collected in Nangarhar, Laghman and Kunar were raised to the adult stage in an insectary located in Jalalabad. To avoid high mortality rate of larvae during transportation, makeshift insectaries were established in dedicated rooms at district hospitals in the provinces of Badakhshan and Ghazni. In all laboratory settings, temperatures were kept at $25 \pm 2{ }^{\circ} \mathrm{C}$ and relative humidity at $75 \pm 10 \%$. Larvae were reared in enamel trays containing water with yeast powder and powdered 
Table 1 Habitat description and localization of sample collection sites

\begin{tabular}{|c|c|c|c|c|c|c|c|}
\hline Province & District & $\begin{array}{l}\text { Malaria risk } \\
\text { strata }\end{array}$ & Village & Habitat type & Elevation (m) & Latitude & Longitude \\
\hline \multirow[t]{7}{*}{ Nangarhar } & Behsood & 1 & Banaghar & Rice field & 551 & $34^{\circ} 26^{\prime} 25.83^{\prime \prime} \mathrm{N}$ & $70^{\circ} 28^{\prime} 56.11^{\prime \prime} \mathrm{E}$ \\
\hline & Behsood & 1 & Samar Khel & Swamps River & 525 & $34^{\circ} 22^{\prime} 39.58^{\prime \prime} \mathrm{N}$ & $70^{\circ} 34^{\prime} 50.33^{\prime \prime} \mathrm{E}$ \\
\hline & Behsood & 1 & Saracha & River/streams & 540 & $34^{\circ} 23^{\prime} 13.70^{\prime \prime} \mathrm{N}$ & $70^{\circ} 32^{\prime} 23.52^{\prime \prime} \mathrm{E}$ \\
\hline & Jalalabad & 1 & Bagrami & Pond/river stream & 571 & $34^{\circ} 26^{\prime} 49.08^{\prime \prime} \mathrm{N}$ & $70^{\circ} 24^{\prime} 24.94^{\prime \prime} \mathrm{E}$ \\
\hline & Kama & 1 & Banajur & Rice field & 545 & $34^{\circ} 26^{\prime} 55.65^{\prime \prime} \mathrm{N}$ & $70^{\circ} 35^{\prime} 6.17^{\prime \prime} \mathrm{E}$ \\
\hline & Kama & 1 & Sabir Kalay & Swamps & 517 & $34^{\circ} 24^{\prime} 40.64^{\prime \prime} \mathrm{N}$ & $70^{\circ} 38^{\prime} 23.19^{\prime \prime} \mathrm{E}$ \\
\hline & Kama & 1 & Sangar Sary & Swamps & 510 & $34^{\circ} 24^{\prime} 8.86^{\prime \prime} \mathrm{N}$ & $70^{\circ} 38^{\prime} 30.71^{\prime \prime} \mathrm{E}$ \\
\hline \multirow[t]{10}{*}{ Laghman } & Alingar & 1 & Kanda Rajaee & River stream & 907 & $34^{\circ} 49^{\prime} 32.44^{\prime \prime} \mathrm{N}$ & $70^{\circ} 21^{\prime} 40.48^{\prime \prime} \mathrm{E}$ \\
\hline & Alingar & 1 & Nowra & River stream & 738 & $34^{\circ} 40^{\prime} 29.38^{\prime \prime} \mathrm{N}$ & $70^{\circ} 14^{\prime} 14.98^{\prime \prime} \mathrm{E}$ \\
\hline & Mihtarlam & 1 & Badee Abad & River stream & 735 & $34^{\circ} 40^{\prime} 15.36^{\prime \prime} \mathrm{N}$ & $70^{\circ} 14^{\prime} 3.79^{\prime \prime} \mathrm{E}$ \\
\hline & Mihtarlam & 1 & Mihtarlam & Pond & 757 & $34^{\circ} 40^{\prime} 24.27^{\prime \prime} \mathrm{N}$ & $70^{\circ} 12^{\prime} 59.50^{\prime \prime} \mathrm{E}$ \\
\hline & Mihtarlam & 1 & Qala-E-Jogi & River stream & 709 & $34^{\circ} 37^{\prime} 59.12^{\prime \prime} \mathrm{N}$ & $70^{\circ} 13^{\prime} 51.92^{\prime \prime} \mathrm{E}$ \\
\hline & Mihtarlam & 1 & Qarghae & River stream & 644 & $34^{\circ} 32^{\prime} 53.46^{\prime \prime} \mathrm{N}$ & $70^{\circ} 14^{\prime} 29.18^{\prime \prime} \mathrm{E}$ \\
\hline & Mihtarlam & 1 & Tirgari & River stream & 735 & $34^{\circ} 38^{\prime} 41.03^{\prime \prime} \mathrm{N}$ & $70^{\circ} 12^{\prime} 36.20^{\prime \prime} \mathrm{E}$ \\
\hline & Qarghayi & 1 & Lal Khana Abad & Pond & 644 & $34^{\circ} 32^{\prime} 44.87^{\prime \prime} \mathrm{N}$ & $70^{\circ} 14^{\prime} 29.31^{\prime \prime} \mathrm{E}$ \\
\hline & Qarghayi & 1 & Swati & River stream & 635 & $34^{\circ} 32^{\prime} 32.76^{\prime \prime} \mathrm{N}$ & $70^{\circ} 15^{\prime} 13.73^{\prime \prime} \mathrm{E}$ \\
\hline & Qarghayi & 1 & Tarrang & River stream & 641 & $34^{\circ} 32^{\prime} 40.76^{\prime \prime} \mathrm{N}$ & $70^{\circ} 14^{\prime} 41.06^{\prime \prime} \mathrm{E}$ \\
\hline \multirow[t]{4}{*}{ Kunar } & Asadabad & 1 & Asadabad & Pond & 830 & $34^{\circ} 52^{\prime} 51.89^{\prime \prime} \mathrm{N}$ & $71^{\circ} 9^{\prime} 37.38^{\prime \prime} \mathrm{E}$ \\
\hline & Asadabad & 1 & Asadabad & Pond & 830 & $34^{\circ} 52^{\prime} 51.89^{\prime \prime} \mathrm{N}$ & $71^{\circ} 9^{\prime} 37.38^{\prime \prime} \mathrm{E}$ \\
\hline & Nurgal & 1 & Nurgal & River stream & 658 & $34^{\circ} 36^{\prime} 45.70^{\prime \prime} \mathrm{N}$ & $70^{\circ} 46^{\prime} 31.76^{\prime \prime} \mathrm{E}$ \\
\hline & Chawkay & 1 & Babur & Pond/river stream & 711 & $34^{\circ} 41^{\prime} 26.04^{\prime \prime} \mathrm{N}$ & $70^{\circ} 56^{\prime} 7.88^{\prime \prime} \mathrm{E}$ \\
\hline \multirow[t]{5}{*}{ Ghazni } & Ghazni & 2 & Koshkak & Pond & 2962 & $34^{\circ} 5^{\prime} 45.61^{\prime \prime} \mathrm{N}$ & $67^{\circ} 30^{\prime} 42.61^{\prime \prime} \mathrm{E}$ \\
\hline & Ghazni & 2 & Pasar & Pond & 2214 & $33^{\circ} 36^{\prime} 32.81^{\prime \prime} \mathrm{N}$ & $68^{\circ} 25^{\prime} 17.71^{\prime \prime} \mathrm{E}$ \\
\hline & Qarabagh & 2 & Mushaki & Water puddle & 2056 & $33^{\circ} 13^{\prime} 49.36^{\prime \prime} \mathrm{N}$ & $68^{\circ} 11^{\prime} 27.53^{\prime \prime} \mathrm{E}$ \\
\hline & Qarabagh & 2 & Pol-E-Qalacha & River stream & 2106 & $33^{\circ} 11^{\prime} 25.23^{\prime \prime} \mathrm{N}$ & $68^{\circ} 4^{\prime} 47.88^{\prime \prime} \mathrm{E}$ \\
\hline & Khwajaumari & 2 & Deh Daran & River stream & 2295 & $33^{\circ} 41^{\prime} 52.34^{\prime \prime} \mathrm{N}$ & $68^{\circ} 23^{\prime} 20.05^{\prime \prime} \mathrm{E}$ \\
\hline \multirow[t]{6}{*}{ Badakhshan } & Baharak & 2 & Baharak & River stream & 1284 & $37^{\circ} 3^{\prime} 6.96^{\prime \prime} \mathrm{N}$ & $70^{\circ} 40^{\prime} 15.95^{\prime \prime} \mathrm{E}$ \\
\hline & Baharak & 2 & Baharak village & Pond & 1300 & $37^{\circ} 3^{\prime} 8.43^{\prime \prime} \mathrm{N}$ & $70^{\circ} 41^{\prime} 24.42^{\prime \prime} \mathrm{E}$ \\
\hline & Fayzabad & 1 & Fayzabad & River stream & 1190 & $37^{\circ} 7^{\prime} 0.96^{\prime \prime} \mathrm{N}$ & $70^{\circ} 34^{\prime} 30.99^{\prime \prime} \mathrm{E}$ \\
\hline & Fayzabad & 1 & Qaria Reggy & Water puddle & 1218 & $37^{\circ} 7^{\prime} 14.02^{\prime \prime} \mathrm{N}$ & $70^{\circ} 34^{\prime} 26.30^{\prime \prime} \mathrm{E}$ \\
\hline & Keshim & 1 & Gundum Qul & River stream & 1014 & $36^{\circ} 47^{\prime} 17.86^{\prime \prime} \mathrm{N}$ & $70^{\circ} 6^{\prime} 49.25^{\prime \prime} \mathrm{E}$ \\
\hline & Keshim & 1 & Jarr-E-Haji Baba & Water puddle & 987 & $36^{\circ} 48^{\prime} 34.04^{\prime \prime} \mathrm{N}$ & $70^{\circ} 5^{\prime} 51.93^{\prime \prime} \mathrm{E}$ \\
\hline
\end{tabular}

fish food supplements. Following pupation, samples were placed in a small bowl with water and transferred to closed cages for their emergence into adults.

\section{Mosquito identification}

Anopheles mosquitoes were identified morphologically at the adult stage using Glick's identification keys [18].

\section{Insecticide susceptibility assays}

Insecticide susceptibility tests were carried out using the WHO bioassay [17]. The following diagnostic concentrations of insecticides were used: $4 \% \mathrm{DDT}, 5 \%$ malathion, $0.1 \%$ bendiocarb, $0.75 \%$ permethrin and $0.05 \%$ deltamethrin. Oil-impregnated papers were used as controls. Test kits and insecticide control oil-impregnated papers were purchased from the Universiti Sains Malaysia (Penang, Malaysia). Filter papers integrity was confirmed using a laboratory-reared An. stephensi strain susceptible to the four classes of insecticides. Susceptibility tests were performed using 3-4 days old female mosquitoes. At least 100 test mosquitoes (20-25 mosquitoes per replicates) and 50 female control mosquitoes (2 replicates) were exposed for $1 \mathrm{~h}$ to each of the insecticide impregnated papers and were then transferred to recovery tubes with a $10 \%$ glucose cotton-impregnated solution. Mortality was recorded $24 \mathrm{~h}$ post exposure. Average mortality was calculated for each insecticide and corrected using Abbot's formula [19] if the observed mortalities in the control 
tests were between 5 and $20 \%$. Tests were discarded if mortality in the control tube was above $20 \%$. WHO criteria were used to assess susceptibility to each insecticide [13]. A mortality rate below $90 \%$ was indicative of resistance while mortality above $98 \%$ indicates susceptibility. Mortality between 90 and $97 \%$ was suggestive of resistance in the population. In total, 224 susceptibility assays including 58 control assays were performed during this study.

For DDT, deltamethrin and permethrin, knock down rate was recorded at 10, 15, 20, 30, 40, 50 and $60 \mathrm{~min}$ in the presence of the corresponding insecticide. After 60 min mosquitoes were transferred to the recovery tube and a last count of the number of knocked down mosquitoes was made at $80 \mathrm{~min}$. A mosquito was considered knocked down if it was unable to stand or fly in a coordinated way.

\section{Knock down resistance allele genotyping}

DNA was extracted from 137 individual mosquitoes following WHO bioassays against deltamethrin (15 alive and 50 dead mosquitoes from Nangarhar and 21 alive and 51 dead mosquitoes from Kunar) using the Qiagen DNeasy blood and tissue kit. $K d r$ genotyping in the Domain II S6 segment of voltage-gated channel gene was performed by two allele-specific PCRs according to the method developed by Singh et al. [17]. The first PCR discriminates the allele 1014F from wild type or $1014 \mathrm{~S}$, and the second PCR discriminates 1014S from wild type allele.

\section{Data and statistical analysis}

Cumulative curves of mortality and $\mathrm{KDT}_{50}$ and $\mathrm{KDT}_{90}$ were calculated with a log time-probit model using Qcal [20]. $2 \times 2$ contingency tables were used to test for association between presence of the $k d r$ allele and survival to deltamethrin in bioassays.

\section{Results}

\section{Larval identification and habitat documentation}

With the exception of Kama district in Nangarhar, the breeding sites visited were mainly uncultivated area corresponding to river banks, ponds or standing water (see summary of ecological habitats in Table 1). All samplings were conducted at altitudes below $2000 \mathrm{~m}$ above sea level (asl) with the exception of Ghazni district where An. stephensi and $A n$. superpictus larvae were collected at altitudes up to $2900 \mathrm{~m}$ asl.

In total, 8834 larvae were collected in the five provinces including 2880 larvae belonging to the Culex group (see Additional file 1). Amongst Anopheles species, $A n$. stephensi was the dominant species (61.9\%) followed by $A n$. culicifacies (20.9\%) and An. superpictus (16.3\%).
Other marginal species found during this study were $A n$. splendidus, $A n$. nigerimus and $A n$. subpictus (all below $1 \%)$. The distribution of Anopheles species in each of the provinces is presented in Fig. 2. An. stephensi was isolated in the provinces south of the Hindu Kush mountain range: in the eastern province of Nangarhar, Kunar and Laghman and in the southern province of Ghazni, as previously documented [4]. Larvae collection in Laghman showed a mixed composition with coexistence of An. culicifacies along with An. stephensi. An. superpictus was isolated in Badakhshan consistent with other observations of its presence in the southern parts of Tajikistan bordering Afghanistan [6]. Overall the malaria vector species identified in this study are consistent with previous bionomic observations performed in Afghanistan [10].

\section{Insecticide susceptibility}

A total of 2049 female mosquitoes, reared from larvae collected in each province, were exposed to insecticides belonging to the four WHO approved classes. Average mortality rates for the dominant species are presented in Fig. 3. Resistance to deltamethrin was observed for An. stephensi (in Nangarhar, Kunar and Ghazni) and $A n$. culicifacies (in Laghman) using a threshold of $90 \%$ mortality for resistance confirmation as set by WHO criteria [21]. Anopheles superpictus in the northern province of Badakhshan showed also incipient pyrethroid resistance with deltamethrin. Resistance to permethrin is less evident as average mortality rates are near or above $90 \%$ for An. stephensi and An. culicifacies, whereas An. superpictus in Badakhshan remains susceptible.

DDT resistance was observed for An. stephensi (in Nangarhar, Kunar and Ghazni) and An. culicifacies in Laghman. However, in Badakhshan An. superpictus remains susceptible to DDT. The three dominant mosquito species analysed in this study remain largely susceptible to

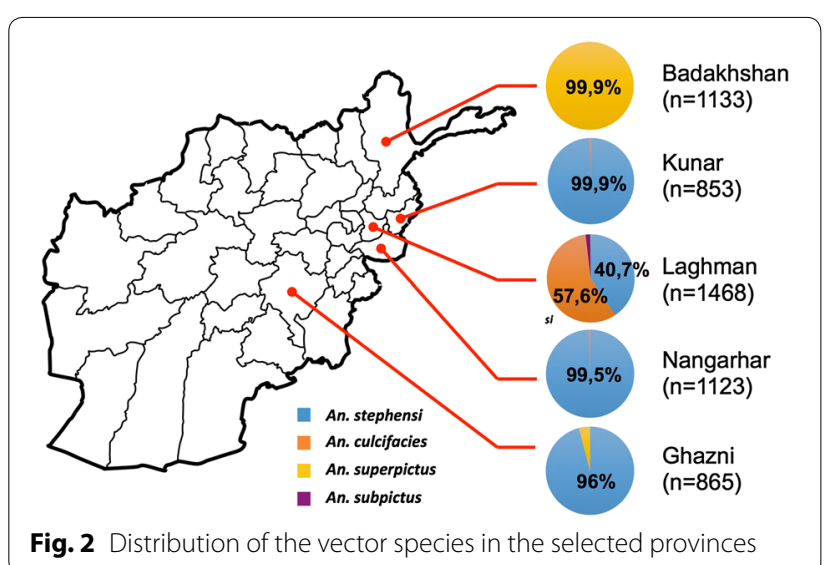




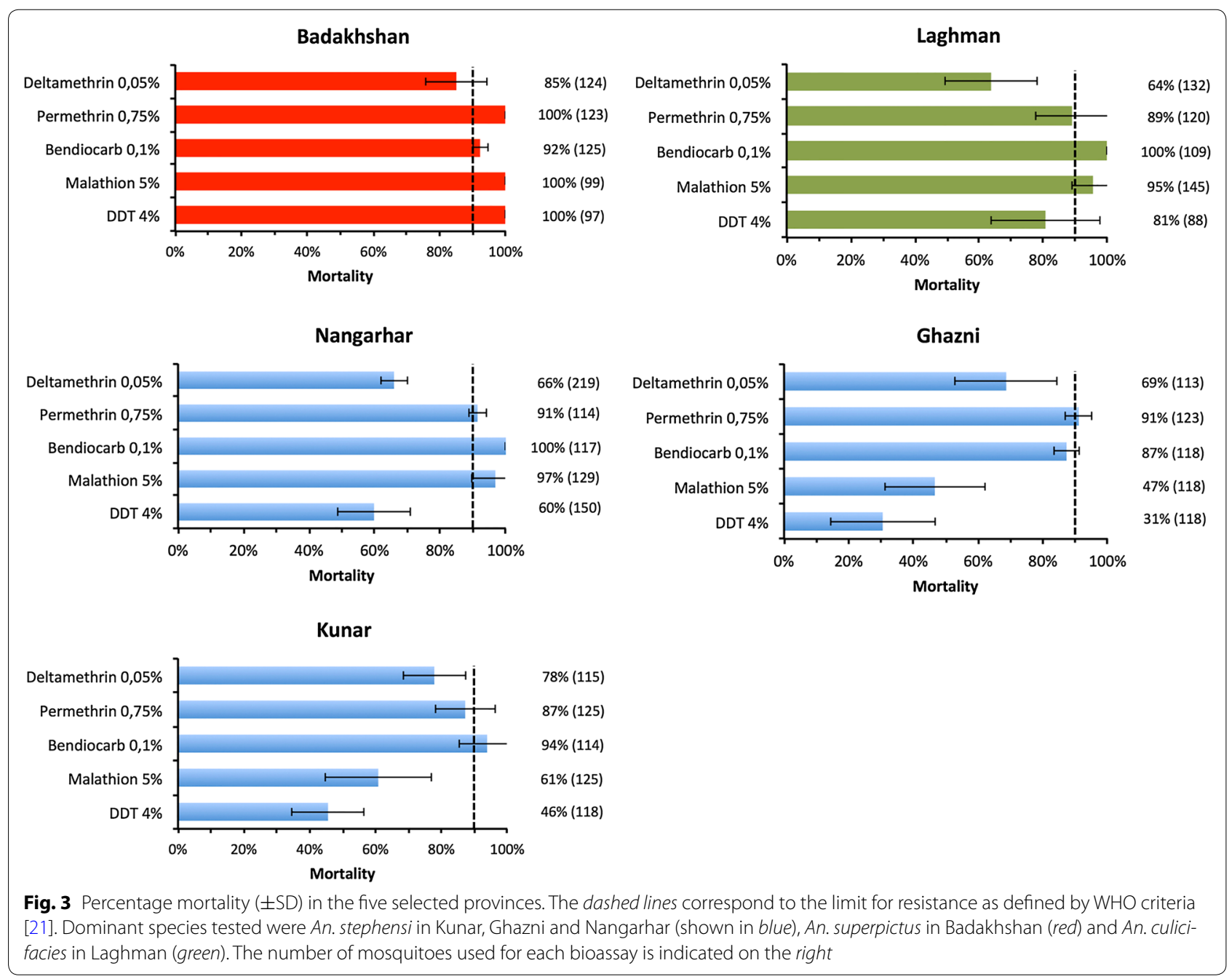

the carbamate insecticide bendiocarb. Finally, contrasting susceptibilities among malaria vectors were observed for malathion as An. superpictus and An. culicifacies were susceptible whereas resistance was detected for An. stephensi mosquitoes collected in Ghazni and Kunar.

The difference in DDT susceptibility between $A n$. superpictus mosquitoes and other malaria vectors was further confirmed by knock down rate analysis (see Fig. 4; Additional file 2). Whereas $90 \%$ of An. superpictus are knocked down after less than $40 \mathrm{~min}$ in the presence of DDT in Badakhshan (KDT $90=37.5$ min, CI $95 \% 3.548-$ 3.702), more than $50 \%$ of An. stephensi or An. culicifacies mosquitoes seems unaffected by this insecticide after $80 \mathrm{~min}$, with $\mathrm{KDT}_{50}$ ranging from 100 to $230 \mathrm{~min}$.

Differences in knock down rates against pyrethroids were also observed between An. stephensi collected in Ghazni and the same species collected in the eastern provinces of Nangarhar and Kunar despite similar $24 \mathrm{~h}$ mortality rates. For example, knock down rates in the presence of deltamethrin is two to three times faster is Ghazni than in Nangarhar or Kunar $\left(\mathrm{KDT}_{50}=17.5 \mathrm{~min}\right.$, CI 95 \% 2.787-2.931; $\mathrm{KDT}_{50}=43.1 \mathrm{~min}$, CI 95 \% 3.6603.865 and $\mathrm{KDT}_{50}=37.3 \mathrm{~min}, 3.534-3.707$, respectively). These variations could suggest different mechanisms of resistance involved in the emerging susceptibility of $A n$. stephensi to pyrethroids in these provinces.

\section{kdr genotyping}

128 of the 137 mosquitoes were successfully genotyped for the $k d r$ alleles indicating that the method developed by Singh et al. [17] in India can also be performed on $A n$. stephensi mosquitoes collected in Afghanistan. In both sites studied, Kunar and Nangarhar, the wild type 1014L allele was the most prevalent allele followed by $1014 \mathrm{~S}$ and 1014F $k d r$ mutations (Fig. 5). No $k d r$ homozygotes were detected, the serine and phenylalanine allele were found 


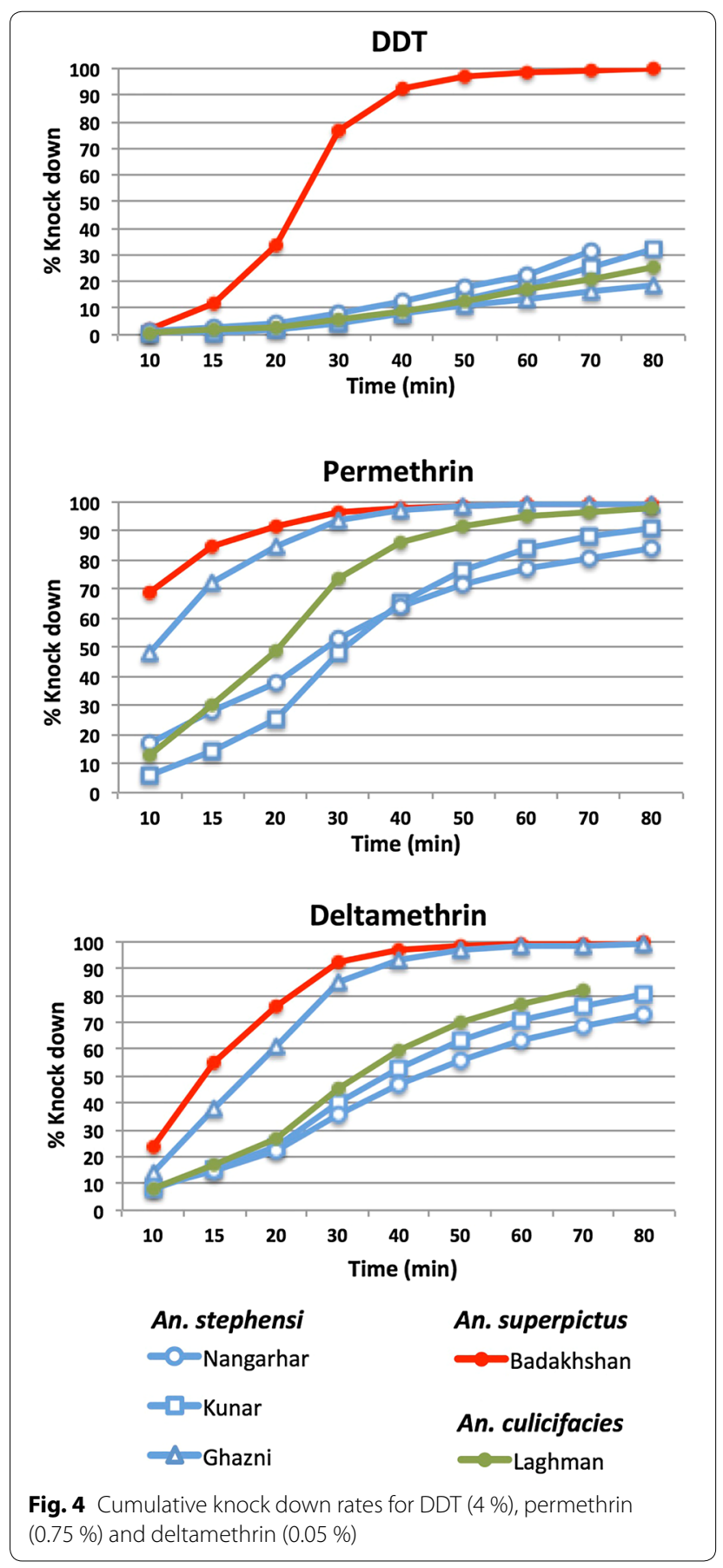

as heterozygotes with the wild type. When data from both sites are combined there is a significant association between the presence of either $k d r$ allele and phenotype $(\mathrm{p}<0.05)$ although the odds ratios are low (2.24). The finding that only $44 \%(15 / 34)$ of the bioassay survivors possessed a $k d r$ mutation suggests that other resistance mechanisms are also present in these populations.

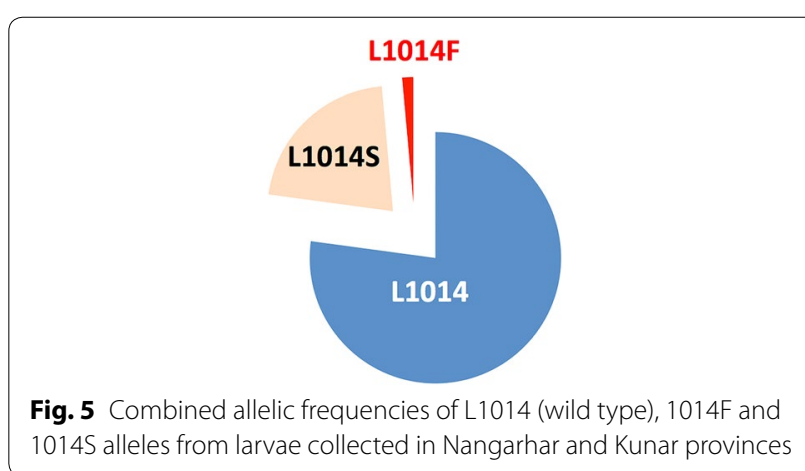

\section{Discussion}

Gathering bionomic information on endemic malaria vectors is an essential component for the development of an effective vector management plan. Previous entomological studies performed in Afghanistan have highlighted the diversity of Anopheles species present in the country $[4,5]$. This study confirmed that An. stephensi and to a lesser extent An. culicifacies are the dominant species in the provinces located in the east (Nangarhar, Laghman and Kunar) and south (Ghazni) of the Hindu Kush mountain range. An. superpictus was the only species identified in the northern province of Badakhshan. Anopheles hyrcanus and An. pulcherrimus have previously been identified in rice fields in the northern province of Kunduz in 2005-2006 [5], but were not detected in the current study. This uneven representation of Anopheles species in northeastern provinces may reflect differences in the densities of irrigated and cultivated areas, in addition to preferences for specific types of ecological habitat within each province [22].

It has been well documented that malaria in Afghanistan is endemic to areas that are below $2000 \mathrm{~m}$ asl although episodes of $P$. falciparum malaria may occur in areas above $2400 \mathrm{~m}$ asl [23]. The presence of An. stephensi and An. superpictus at high altitudes (up to $2900 \mathrm{~m}$ asl) in Ghazni is therefore not surprising and highlights the distribution of the vectors to a variety of environmental conditions. With the exception of rice fields in Nangarhar, the three dominant species identified in this study (An. superpictus, An. culicifacies and An. stephensi) were collected from freshwater breeding site and ponds. As larvae collections were performed during 2-3 weeks successively in each province, the relative representation of Anopheles species in each of the provinces may well vary during the malaria transmission season.

Adults reared from the dominant larvae species found in each of the five provinces (An. stephensi in Nangarhar, Kunar and Ghazni, An. culicifacies in Laghman and An. superpictus in Badakhshan) were used as test subjects 
to measure the level of insecticide resistance using the WHO test procedure [21]. Overall, insecticide resistance was observed (or highly suspected) to at least pyrethroids and DDT. The situation in Badakhshan is different from the other provinces as An. superpictus mosquitoes from that province were susceptible to all insecticides tested with the exception of deltamethrin for which emerging resistance is suspected.

It is now evident that pesticide usage from agriculture activities and increased coverage of LLINs in vector control can directly select for insecticide resistance $[24,25]$. Despite a lack of data on precise pesticide usage in Afghanistan, it is likely that pest control activities have consequences on mosquito populations and could potentially lead to cross-resistance with the insecticides used in malaria vector control activities. Such selection pressure could be even more exacerbated in Afghanistan where potential mosquito breeding sites and rice fields are closely associated and restricted to valleys. A limited number of irrigation infrastructures and less agricultural areas compared to other provinces could thus explain the relative susceptibility observed for An. superpictus mosquitoes collected in Badakhshan, although it is possible that this species is more sensitive to the standard doses of insecticide used in this study. Additive or synergistic effects with pesticides in provinces with more intensive agriculture and irrigation could also be determinant in the observed resistance, as cross-resistance has previously been described in other countries [24]. Beside the dispersion of resistant mosquitoes from neighbouring provinces, the observed resistance in Ghazni could be an example of such crossresistance as bed nets distribution has been implemented only recently (HealthNet TPO, personal data).

Massive distribution of deltamethrin-impregnated LLINs in Afghanistan over the past decade is a likely contributor to the emerging deltamethrin insecticide resistance that was observed. The LLINs that were distributed since 2007 are impregnated with deltamethrin (PermaNet 2.0). In Badakhshan, irrigation is less developed compared to other Afghan provinces and agriculture is more oriented towards pastoral activities. The resistance to pyrethroid (at least deltamethrin) observed for An. superpictus Badakhshan is thus most likely a direct consequence of the bed net distribution campaigns as crop production and irrigation infrastructure is less developed in this province.

Understanding the mechanisms of resistance is essential to adapt vector control strategies and helps predict the origin (new emergence versus migration of resitant populations) and likely impact of resistance [13]. So far analysis of the underlying mechanisms of resistance has not been done in Afghanistan. Although a method has been developed to genotype $k d r$ mutations in $A n$. stephensi mosquitoes in India [17], DNA sequence variations at the $v g c$ locus may have reduced the fidelity of this genotyping protocol. The implemented study aimed initially to test if this method can be effectively applied using An. stephensi mosquitoes collected in Afghanistan. PCR amplicons were successfully obtained at the kdr locus in $93 \%$ of the mosquitoes tested (128 out of 137) indicating that this methodology can be used with no additional optimization of the reaction conditions. Therefore, this is a new tool available for vector and malaria control programmes in Afghanistan to understand and follow up acquired resistance against pyrethroids.

In addition, this study provided information on the relative distribution of $k d r$ mutations relative to the wild type allele. The pattern of L1014S and L1014F mutations is similar to observations in India with L1014S being more prevalent than L1014F. No homozygote $k d r$ mutations were observed, although a relatively low sample size (restricted to the eastern provinces of Nangarhar and Kunar) was used in this study. Finally, as some deltamethrin-resistant mosquitoes do not express mutated forms of the $v g c$ gene, other mechanisms of resistance must be considered to explain this phenotype.

\section{Conclusions}

This study showed that insecticide resistance is now emerging within malaria vectors in Afghanistan and highlights the importance of establishing an insecticide resistance management plan [26]. The observation that the pattern of insecticide susceptibility varies amongst the different Anopheles species and ecological contexts advocates for additional bionomic studies associated with insecticide resistance monitoring in all malaria endemic provinces. The impact of the current levels of resistance on the efficacy of LLINs is not known. However, as theory and practice both indicate that levels of pyrethroid resistance in malaria vectors will continue to increase, this must be carefully monitored and complementary interventions implemented if there is indication that the protective efficacy of LLINs is diminished by insecticide resistance in Afghanistan.

\section{Additional files}

Additional file 1: Table S1. Species distribution in each district and provinces.

Additional file 2: Table S2. $50 \%$ and $90 \%$ knock down time in minutes (KDT50 and KDT90 respectively) for DDT, permethrin and deltamethrin.

\section{Abbreviations}

asl: above sea level; DDT: dichlorodiphenyltrichloroethane; GPIRM: global plan for insecticide resistance management; IRS: indoor residual spraying; kdr: knock down resistance; $\mathrm{KDT}_{50}: 50 \%$ knock down time; $\mathrm{KDT}_{90}: 90 \%$ knock down time; LLIN: long-lasting insecticidal net; MoPH: Ministry of Public Health; NMLCP: National Malaria and Leishmaniasis Control Programme; PCR: polymerase chain reaction; WHO: World Health Organization. 


\section{Authors' contributions}

$M A, C B$ and $M V$ designed the study and drafted the manuscript. MA led the larval collection, mosquito rearing and bioassay testing. PP and HR performed molecular analysis of kdr status. SMN, MN, MF and AMS helped with the study design and implementation. CB, MV and HR carried out statistical analysis. All authors read and approved the final manuscript.

\section{Author details}

${ }^{1}$ HealthNet TPO, Kabul, Afghanistan. ${ }^{2}$ ORDiagnostics, 10 rue Irénée Blanc, 75020 Paris, France. ${ }^{3}$ Liverpool School of Tropical Medicine, Pembroke Place, Liverpool L3 5QA, UK. ${ }^{4}$ National Malaria and Leishmaniasis Control Programme, Ministry of Public Health, Kabul, Afghanistan. ${ }^{5}$ HealthNet TPO, Lizzy Ansinghstraat 163, 1072 RG Amsterdam, The Netherlands.

\section{Acknowledgements}

The authors wish to thank Abdul Ali and Noor Halim from NMLCP and Abdullah Nazari and Abdul Rauf from HealthNet TPO for assistance in the larvae collection and bioassay testing. This work was supported by a grant from the Global Fund to Fight AIDS, Tuberculosis and Malaria (AFG 809-G09M) to HealthNet TPO.

\section{Competing interests}

The authors declare that they have no competing interests.

Received: 7 November 2015 Accepted: 4 February 2016 Published online: 18 February 2016

\section{References}

1. WHO. World malaria report. Geneva: World Health Organization; 2014.

2. Kolaczinski J, Graham K, Fahim A, Brooker S, Rowland M. Malaria control in Afghanistan: progress and challenges. Lancet. 2005;65:1506-12.

3. Brooker S, Leslie T, Kolaczinski K, Mohsen E, Mehboob N, Saleheen S, et al. Spatial epidemiology of Plasmodium vivax, Afghanistan. Emerg Infect Dis. 2006;12:10-2.

4. Rowland M, Mohammed N, Rehman H, Hewitt S, Mendis C, Ahmad M, et al. Anopheline vectors and transmission of malaria in eastern Afghanistan. Trans R Soc Trop Med Hyg. 2002;96:620-6.

5. Faulde MK, Hoffmann R, Fazilat KM, Hoerauf A. Malaria reemergence in northern Afghanistan. Emerg Infect Dis. 2007;13:1402-4.

6. Habirov Z, Kadamov D, Iskandarov F, Komilova S, Cook S, McAlister E, et al. Malaria and the Anopheles mosquitoes of Tajikistan. J Vector Ecol. 2012;37:419-27

7. Sinka ME, Bangs MJ, Manguin S, Coetzee M, Mbogo CM, Hemingway J, et al. The dominant Anopheles vectors of human malaria in Africa, Europe and the Middle East: occurrence data, distribution maps and bionomic précis. Parasites Vectors. 2010;3:117.

8. White MT, Conteh L, Cibulskis R, Ghani AC. Costs and cost-effectiveness of malaria control interventions: a systematic review. Malar J. 2011;10:337.

9. Bhatt S, Weiss DJ, Cameron E, Bisanzio D, Mappin B, Dalrymple U, et al. The effect of malaria control on Plasmodium falciparum in Africa between 2000 and 2015. Nature. 2015;526:207-11.

10. Ministry of Public Health Islamic Republic of Afghanistan. National Malaria Strategic Plan 2013-2017.
11. WHO. Insecticides for IRS. Geneva, Switzerland, World Health Organization. http://www.who.int/whopes/en/.

12. WHO. Pesticide Evaluation Scheme: Pesticides and their application for the control of vectors and pests of public health importance. WHO/CDS/ NTD/WHOPES/GCDPP/2006.1.

13. WHO. Global plan for insecticide resistance management in malaria vectors (GPIRM). Geneva: World Health Organization; 2012.

14. Nejati J, Vatandoost H, Oshghi MA, Salehi M, Mozafari E, Moosa-Kazemi $\mathrm{SH}$. Some ecological attributes of malarial vector Anopheles superpictus Grassi in endemic foci in southeastern Iran. Asian Pac J Trop Biomed. 2013;3:1003-8.

15. Enayati AA, Vatandoost H, Ladonni H, Townson H, Hemingway J. Molecular evidence for a kdr-like pyrethroid resistance mechanism in the malaria vector mosquito Anopheles stephensi. Med Vet Entomol. 2003;17:138-44.

16. Knox TB, Juma EO, Ochomo EO, Pates Jamet $H$, Ndungo L, Chege P, et al. An online tool for mapping insecticide resistance in major Anopheles vectors of human malaria parasites and review of resistance status for the Afrotropical region. Parasit Vectors. 2014;7:76.

17. Singh OP, Dykes CL, Lather M, Agrawal OP, Adak T. Knockdown resistance $(\mathrm{kdr})$-like mutations in the voltage-gated sodium channel of a malaria vector Anopheles stephensi and PCR assays for their detection. Malar J. 2011;10:59.

18. Glick Jl. Illustrated key to the female Anopheles of southwestern Asia and Egypt (Diptera: Culicidae). Mosq Syst. 1992:4:125-53.

19. Abbott WS. A method of computing the effectiveness of an insecticide. J Econ Entomol. 1925;18:265-7.

20. Lozano-fuentes AS, Saavedra-rodriguez K, Black WC, Eisen L. QCal: a software application for the calculation of dose-response curves in insecticide resistance bioassays. J Am Mosq Control Assoc. 2012;28:59-61.

21. WHO. Test procedures for insecticide resistance monitoring in malaria vector mosquitoes. Geneva: World Health Organization; 2013.

22. Country information in Afghan Agriculture UCDavis: http://afghanag. ucdavis.edu/country-info/.

23. Abdur Rab M, Freeman TW, Rahim S, Durrani N, Simon-Taha A, Rowland M. High altitude epidemic malaria in Bamian province, central Afghanistan. East Mediterr Health J. 2003;9:232-9.

24. Corbel V, Guessan RN. Distribution, mechanisms, impact and management of insecticide resistance in malaria vectors: a pragmatic review. In: Manguin S, editor. Anopheles mosquitoes—new insights into malaria vectors. InTech: Rijeka; 2013. p. 579-633.

25. Ranson H, Abdallah H, Badolo A, Guelbeogo WM, Kerah-Hinzoumbé C, Yangalbé-Kalnoné E, et al. Insecticide resistance in Anopheles gambiae: data from the first year of a multi-country study highlight the extent of the problem. Malar J. 2009;8:299.

26. Mnzava AP, Knox TB, Temu EA, Trett A, Fornadel C, Hemingway J, et al. Implementation of the global plan for insecticide resistance management in malaria vectors: progress, challenges and the way forward. Malar J. $2015 ; 14: 173$.

\section{Submit your next manuscript to BioMed Central and we will help you at every step:}

- We accept pre-submission inquiries

- Our selector tool helps you to find the most relevant journal

- We provide round the clock customer support

- Convenient online submission

- Thorough peer review

- Inclusion in PubMed and all major indexing services

- Maximum visibility for your research

Submit your manuscript at www.biomedcentral.com/submit

C Biomed Central 